\title{
A DUPLA FUNÇÃO DAS IDEOLOGIAS A PARTIR DAS CONTRIBUIÇÕES DE LUKÁCS E LEFEBVRE
}

\author{
Carlos Fernando Torres Oviedo ${ }^{1}$
}

\section{Resumo}

Apresenta-se uma reflexão teórica que proporciona um ponto de convergência analítica sobre as ideologias como artefatos abstratos que têm - de modo simultâneo - duas funções práticas: 1) afastar a consciência humana do ser social (no plano das idéias) e, 2) organizar a vida cotidiana (no plano real concreto). Assim, propõe-se superar tanto a concepção neutra e subjetivista das ideologias como visão de mundo, quanto o critério gnosiológico para defini-las. Desse modo, destacam-se ao mesmo tempo a crítica ontológica e a critica à vida cotidiana, como duas dimensões de análise que permitem entender as ideologias de modo inseparável da ação do ser humano na sociedade de classes.

Palavras-chave: Ideologias. Crítica Ontológica. Crítica da Vida Cotidiana. Estudos Organizacionais.

\section{THE DOUBLE FUNCTION OF IDEOLOGIES FROM THE CONTRIBUTIONS OF LUKÁCS AND LEFEBVRE}

\begin{abstract}
This article presents a theoretical reflection that provides a point of analytical convergence on ideologies as abstract devices that have simultaneously - two practical functions: 1) to distance human consciousness from social being (at the level of ideas) and 2) to organize the everyday life (on the concrete real plane). Thus, it is proposed to overcome both the neutral and subjectivist conception of ideologies as a worldview, as well as the gnoseological criterion to define them. In this way, the ontological critique and the critique of everyday life are highlighted, as two dimensions of analysis that allow the understanding

\footnotetext{
${ }^{1}$ Doutorando do Programa de Pós-Graduação da Escola de Administração da Universidade Federal do Rio Grande do Sul, Área de Estudos Organizacionais. Bolsista da Coordenação de Aperfeiçoamento de Pessoal de Nível Superior (CAPES). O autor agradece o apoio do grupo de pesquisa Organização e Práxis Libertadora, coordenado pela professora Maria Ceci Araujo Misoczky. E-mail: carlos.oviedo@ufrgs.br
}

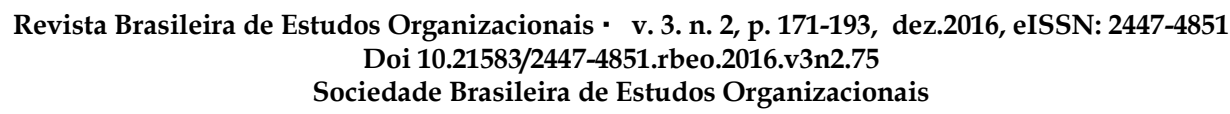


of ideologies inseparably from the action of the human being in class societies.

Keywords: Ideologies. Ontological Critique. Critique of Everyday Life. Organizational Studies.

\section{LA DOBLE FUNCIÓN DE LAS IDEOLOGÍAS A PARTIR DE LAS CONTRIBUCIONES DE LUKÁCS Y LEFEBVRE}

\section{Resumen}

Se presenta una reflexión teórica que proporciona un punto de convergencia analítica sobre las ideologías como artefactos abstractos que tienen - de modo simultáneo - dos funciones prácticas: 1) alejar la conciencia humana del ser social (en el plano de las ideas) y, 2) organizar la vida cotidiana (en el plano real concreto). Así, se propone superar tanto la concepción neutra y subjetivista de las ideologías como visión del mundo, como el criterio gnoseológico para definirlas. De este modo, se destacan al mismo tiempo la crítica ontológica y la crítica a la vida cotidiana, como dos dimensiones de análisis que permiten entender las ideologías de modo inseparable de la acción del ser humano en las sociedades de clases.

Palabras clave: Ideologías. Crítica Ontológica. Crítica de La Vida Cotidiana. Estudios Organizacionales.

\section{Introdução}

O presente texto defende o argumento de que nos trabalhos de György Lukács e de Henri Lefebvre há um ponto de convergência analítica sobre as ideologias como artefatos que têm funções práticas. Essas funções expressam-se através de dois movimentos simultâneos e complementares: no primeiro, acontece uma espécie de afastamento da consciência humana para figurações sobre o mundo que não correspondem ao que ele é; no segundo, a vida cotidiana, em tanto espaço concreto de reprodução das relações sociais, é organizada como modos de vida coerentes com essas figurações.

A convergência nos trabalhos de Lukács e Lefebvre sobre as ideologias como funções práticas será elaborada a partir das discussões colocadas por estes autores sobre a crítica ontológica e a crítica da vida 
cotidiana ${ }^{2}$, questões que permitem configurar um espaço analítico comum como base para futuras pesquisas no campo dos Estudos Organizacionais. É esse o horizonte que inspira este ensaio, um campo acadêmico no qual navego na busca de referenciais que permitam explicar o fenômeno ideológico, e que considerei num primeiro momento, como simplesmente uma visão de mundo - irracional e dogmática - que fundamenta as crenças de grupos sociais sobre eles mesmos e sua posição social. Uma concepção muito próxima do senso comum sobre as ideologias. Agora, no momento em que me encontro, adoto uma concepção crítica baseada em autores que ressaltam o caráter prático das ideologias na resolução de problemas decorrentes das contradições próprias da sociedade de classes. Resolução necessária para sua reprodução.

Adicionalmente, as divergências que podem ser achadas entre as obras de Lukács e Lefebvre não serão ponto de referência no presente ensaio, portanto considero importante advertir que não se trata de fazer um estudo comparativo das elaborações de dois autores para estabelecer semelhanças e diferenças. A pretensão dirige-se para conformar uma tentativa de síntese em torno de uma mesma preocupação intelectual dos autores: atualizar o pensamento marxista a partir de novas questões teóricas e práticas que eles observaram no século XX, e que abordaram através de seu próprio caminho ${ }^{3}$.

A respeito disso, Michel Trebitsh (1991), autor do Prefácio da edição em inglês do livro de Lefebvre (1991a) - Crítica da Vida Cotidiana observa que

O pleno significado da relação entre Lukács e Lefebvre emerge claramente se não se pensa em termos de influência, mas em termos de dois intelectuais viageiros paralelos, mas separados cronologicamente, orientados pela ontologia do marxismo. Em $\mathrm{La}$ Somme et Ie reste Lefebvre lembra que sua descoberta da teoria da alienação foi como um "flash de inspiração": para chegar a seus próprios conceitos de mistificação, do homem total e da crítica da vida cotidiana, ele teve que trabalhar uma inversão do mesmo

2 A escolha de estes dois elementos foi feita a partir da leitura de alguns dos textos produzidos por eles, já que a obra de cada um é bastante ampla. Mas também pela aproximação do autor através de um processo que ainda está em andamento. As fontes bibliográficas foram por parte de Lukács (2012): Para uma Ontologia do Ser Social; por parte do Lefebvre (1991a): Crítica da Vida Cotidiana.

${ }^{3}$ Cada um deles conheceu e valorou a obra do outro, mas não há algum trabalho feito em conjunto. Lukács faz uma menção explícita ao trabalho de Lefebvre no prólogo do livro de Agnes Heller (2002): Sociologia da Vida Cotidiana. Lefebvre, por sua parte, menciona o trabalho de Lukács ao longo dos três tomos da Crítica da Vida Cotidiana, mas resulta interessante destacar uma palestra intitulada "Lukács 1955" no Instituto Húngaro de Paris, feita em sua homenagem. Consequentemente, acho importante fazer mais um esclarecimento: o presente ensaio não está focado nesse conjunto de alusões explícitas justamente porque não é esse o objetivo. Ao invés disso serão analisadas as considerações de cada um sobre as ideologias como funções práticas nos textos mencionados. 
tipo como Lukács enquanto ele passou do conceito de vida inautêntica ao conceito da reificação da consciência (TREBITCH, 1991, p. 16).

Assim, essa relação que emerge é expressa ao longo da obra de cada um deles por meio de seus trabalhos feitos em torno de várias categorias, entre as quais se destaca a teoria da alienação (tema que será abordado mais adiante neste ensaio). Em consequência, este texto ensaia as contribuições que de modo paralelo foram desenvolvidas por Lukács e Lefebvre em torno das ideologias, tanto na sua função - no plano das ideias - de afastar o ser humano da consciência do mundo real, quanto na sua função - no plano do real concreto - de organizar a vida cotidiana.

Para começar, considero importante colocar a dificuldade inerente ao termo ideologia. A esse respeito, não poucos autores comentam tanto a polissemia quanto a ambiguidade tecida em torno dele. Nesse sentido, optar por uma definição fechada e operacionalizada não contribuiria muito para refletir sobre suas consequências práticas. No entanto, vale a pena apreciar a trajetória que Leandro Konder (2002) faz desta noção, desde as primeiras preocupações na Grécia Antiga até as tentativas iniciais de demarcação na modernidade no momento em que, no contexto da Revolução Francesa, Antoine Destutt de Tracy o utilizou pela primeira vez para nomear uma área da filosofia que constituiria "o fundamento de todas as ciências", no sentido da produção de ideias. Diante das múltiplas acepções do termo, Konder (2002) recupera a distinção de Stoppino (1986) entre o significado fraco (conceito neutro) e forte (crítico e negativo) de ideologia. Assim, Konder (2002) delineia uma diferenciação entre aproximações antes e depois dos trabalhos de Marx, a partir do livro "A Ideologia Alemã" (MARX e ENGELS, 1974). Mesmo que nele não haja uma conceituação explícita de ideologia, o termo é utilizado no sentido crítico para se referir aos fundamentos do grupo dos "jovens hegelianos" que dominavam o pensamento filosófico no século XIX.

A partir do século XX, "a questão filosófica da ideologia cedia lugar a um campo de estudos bem mais restrito, que ficava entregue à competência exclusiva dos sociólogos, incumbidos de verificar a que grupos, classes ou setores da sociedade se ligavam as representações ideológicas" (KONDER, 2002, p. 55).

Sob esta perspectiva, destaca-se o trabalho de Teun van Dijk (1999, p. 92) - desde uma aproximação sócio-cognitiva do discurso - que define ideologia em termos de crenças fundamentais que são a base das representações sociais compartilhadas pelos membros de um grupo. Para van Dijk (1999, p. 92), explicitamente, as ideologias são “sistemas básicos de cognição social, conformados pelas representações mentais compartilhadas e específicas para um grupo, que estão dentro das crenças 
gerais (conhecimento, opiniões, valores, critérios de verdade etc.) de sociedades inteiras ou culturas". As abordagens marxistas, por sua vez, assumem toda ideologia na sua essência crítica e negativa, e vão além da dimensão subjetivista para dar conta das implicações práticas na realidade, como as desenvolvidas por Lukács e Lefebvre que serão trabalhadas neste ensaio. Em razão disso, é preciso explicar a fundamentação ontológica destes autores, já que ela constitui a base que permite articular a aproximação de cada um deles sobre as ideologias.

\title{
As bases ontológicas da crítica marxista das ideologias
}

A possibilidade analítica de articular as aproximações de Lukács e Lefebvre - no que é assumido como ideológico - pode ser fundamentada a partir dos elementos que eles simultaneamente retomam da ontologia implícita no processo de desenvolvimento do pensamento de Marx. A dimensão ontológica, quer dizer, o que é o mundo e o que existe nele e, portanto, o que o ser humano é, pode ser caracterizada a partir de uma dupla determinação. O ser humano é, ao mesmo tempo, um ser biológico (com as mesmas necessidades fisiológicas dos demais animais) que faz parte da natureza, e um ser social (com consciência sobre si mesmo e o mundo) próprio dos processos históricos. Este postulado foi enunciado pela primeira vez na obra de Marx de modo não explícito, mas Lukács (2012, p.284) recorre a esses textos afirmando que

\begin{abstract}
No momento em que Marx faz da produção e da reprodução da vida humana o problema central, surgem, tanto no próprio ser humano como em todos os seus objetos, relações, vínculos etc. como dupla determinação de uma insuperável base natural e de uma ininterrupta transformação social dessa base [...] Não se pode considerar o ser social como independente do ser da natureza, como antítese que o exclui, o que é feito por grande parte da filosofia burguesa quando se refere aos chamados "domínios do espírito". De modo igualmente enérgico, a ontologia marxiana do ser social exclui a transposição simplista, materialista vulgar, das leis naturais para a sociedade, como era moda, por exemplo, na época do "darwinismo social" (LUKÁCS, 2012, p. 285-286).
\end{abstract}

Temos, aqui, uma ontologia materialista da natureza que se contrapõe às aproximações tanto idealistas quanto positivistas do que é o mundo. Para Lukács (2012), esse é o ponto de partida filosófico de Marx (2008) na construção de uma ontologia claramente diferenciada do 
pensamento dominante da época (século XIX) e procurando desde cedo para seus estudos econômicos, a crescente concretização de conexões do ser social dos homens com seu ser orgânico e inorgânico. Essa tendência está presente no livro Manuscritos Econômicos e Filosóficos (2008), texto que tem uma especial originalidade pelo fato de que, "[...] pela primeira vez na história da filosofia, as categorias econômicas aparecem como categorias da produção e da reprodução da vida humana, tornando assim possível uma exposição ontológica do ser social sobre bases materialistas" (LUKÁCS, 2012, p. 285).

Diz Lukács (2012) que Marx sempre se posicionou contrário à tradicional separação entre natureza e sociedade, reconhecendo apenas a ciência da história, que abrange tanto o conhecimento sobre a natureza quanto o conhecimento sobre o mundo humano. No primeiro desses aspectos, a base natural, Marx (2008) concorda com os postulados centrais da teoria darwiniana. Nesse sentido, o homem é, enquanto ser biológico, decorrente de um longo processo de evolução. No segundo, o processo de transformação social, Marx (2008) coloca como elemento mediador, o trabalho humano. Nesse sentido, o mundo humano é também decorrente do processo de criação das suas próprias condições de vida material. Portanto, o trabalho emerge como categoria central e condição de existência do homem, independentemente de quaisquer que sejam as formas sociais nas quais ele está inserido. $\mathrm{O}$ trabalho torna-se, então, um mediador no metabolismo entre homem e natureza e, portanto, da vida humana.

O trabalho gera uma dupla transformação. Por um lado, o próprio ser humano é transformado por causa de seu trabalho. Por outro, os objetos da natureza são transformados em novos objetos, assim como as matérias-primas que, por sua vez, são utilizadas para gerar mais objetos necessários para a vida humana. Se através do trabalho, os objetos naturais podem ser convertidos em coisas úteis, essa conversão envolve um processo deliberadamente pensado. Em outras palavras, ele é um processo de previsão e concreção de um determinado fim, "um pôr teleológico". Isto é, um processo realizado para obter um determinado objetivo, portanto ele implica na existência da consciência humana como característica diferenciadora entre homens e animais. Cada objeto produzido esteve inicialmente presente na imaginação do homem enquanto ser trabalhador - desde o início do processo. Este processo envolve sempre ideação consciente e implementação das faculdades humanas - uma práxis - realizadas em condições específicas e colocadas num contexto real.

Com essas considerações, Lukács esclarece a superação dos pensamentos vigentes na sua época, no século XIX. Deste modo, Marx (2008) configura o que Lukács (2012) denominou como "salto ontológico", 
no sentido de que o ser social pressupõe o ser de natureza inorgânica e de natureza orgânica. Já a filosofia burguesa exclui os dois domínios. A ontologia marxista do ser social, no entanto, ultrapassa tanto a idealização do ser humano como direcionado só para um único espírito prédeterminado, quanto a transposição simplista de leis naturais para a sociedade. Aqui está o debate tanto para a filosofia idealista alemã, quanto para a interpretação puramente organicista da sociologia britânica - cada uma delas com sua própria base ontológica.

Então, o que Lukács chama de salto ontológico consiste na virada filosófica para a incorporação da dupla determinação do ser humano que contém elementos tanto histórico-sociais quanto naturais. $\mathrm{Na}$ posição de Marx (2008) há, então, uma indissolúvel unidade materialista entre esses elementos. Desse modo, assistimos à "[...] fundação de uma ontologia materialista da natureza, que compreenda em si a historicidade e a processualidade, a contraditoriedade dialética, etc., [que] já está implicitamente contida no fundamento metodológico da ontologia marxiana" (LUKÁCS, 2012, p. 289).

Nesse sentido, Lefebvre (1991a) desenvolve sua análise sobre a vida cotidiana assumindo também a ontologia marxista que considera tanto a existência da realidade - no seu caráter histórico e contraditório - quanto o lugar do homem como um ser imerso e ativo nessa realidade:

A crítica da vida cotidiana analisa a "vida", como ela é, sem fazer uma entidade obscura dela; estuda os elementos negativos e positivos que confrontam uns aos outros; estuda os novos conflitos e as novas contradições no que é novo, sabendo que o novo é (mais ou menos) em todos os lugares. . . Assim, sabe-se que o novo homem tem de resolver suas próprias contradições, a fim de desenvolver-se como um homem (LEFEBVRE, 1991a, p. 66).

Assim, Lefebvre (1991a) também assume o homem como um ser com a dupla determinação que Lukács (2012) analisou em Marx (2008):

O ser do homem é, ao mesmo tempo natural e histórico, biológico e social, fisiológico e cultural (o que não exclui conflitos possíveis ou reais entre esses elementos e aspectos - pelo contrário, envolve-os). $\mathrm{O}$ homem pensa porque ele tem um cérebro ( $\mathrm{a}$ atividade superior do sistema nervoso) e porque ele tem mãos, $\mathrm{e}$ porque ele trabalha e porque tem uma linguagem. Portanto, a consciência reflete essas interações múltiplas; ele não só "reflete" o mundo exterior e as coisas, mas também a atividade humana, $\mathrm{o}$ poder prático sobre a natureza (LEFEBVRE, 1991a, p. 95).

A discussão e o posicionamento sobre o que o ser humano é constitui um debate, que leva a explicitar os princípios assumidos pelas 
tradições filosóficas. A crítica postulada por Lukács, então, está baseada nos pressupostos ontológicos assumidos pelas objetivações que teorizam sob uma lógica de pensamento que é suficiente por si só. Tal crítica deverá ser localizada no contexto do século $X X$, no momento em que a tradição positivista declara que o importante na atividade científica não é mais saber o que são as coisas, mas saber como as coisas funcionam. Para essa tradição filosófica, o que importa é produzir modelos para poder operacionalizar e manipular a realidade. A ciência abandona a questão do ser - como problema importante - ao assumir um tipo particular de ser, ahistórico e imutável.

Nesse sentido, para Duayer (2012), a crítica ontológica de Lukács não foi feita para erguer declarações epistemológicas sobre a elaboração de teorias cada vez mais sofisticadas para a sua própria autorreflexão. Em vez disso, se trata de salientar os fundamentos que sustentam tanto as práticas como as objetivações da realidade. Desse modo, cada tentativa de apreender o mundo pressupõe uma ontologia. A crítica nesse nível está focada nos postulados filosóficos básicos, na "fonte de seus axiomas estruturantes" (DUAYER, 2012, p. 39), em outras palavras

[...] a crítica ontológica, pelo contrário, dirige-se em especial aos pressupostos estruturais da tradição criticada. Em conseqüência, tem de ser uma crítica que refigura o mundo, que põe $e$ pressupõe outra ontologia. É justamente nesse sentido que a crítica de Marx é crítica ontológica - no caso, crítica da sociedade capitalista, da formação socioeconômica posta pelo capital (DUAYER, 2012, p. 40).

Assumir um ser humano com a dupla determinação - natural e social - permite postular que as formações sociais são igualmente históricas e, por conseguinte, suscetíveis de transformação através da consciência humana ${ }^{4}$. Por isso, a busca de Lefebvre (1991a), no seu estudo da vida cotidiana, consiste em substituir o real pelo possível. Em outras palavras, por um novo real. Assim, assume também a existência do real, mas não se conforma com contemplar o mundo. Essa atitude transformadora da realidade foi colocada em debate contra o pensamento dominante. Não por acaso, Lefebvre (1991a) também (assim como Lukács, 2012) problematiza a filosofia positivista do século XIX e a sua apropriação nas ciências sociais daquela época até as suas tentativas de continuidade no século XX. Em palavras de Michel Trebitch (1991, p. 11), “devemos notar que a recusa tanto da atitude puramente fenomenológica em relação à consciência quanto do pessimismo heideggeriano era a força do desafio

\footnotetext{
${ }^{4}$ Aqui é necessário apontar que para Lefebvre (1991a, p. 38) a consciência é ao mesmo tempo estruturada e estruturante. 
do Lefebvre ao existencialismo no pós-guerra". Também discute que, para essa tendência, a vida cotidiana é apresentada como não filosófica, separada da vida real. Lefebvre (1991b) assinala que o filósofo cai numa falsa dicotomia entre filosofia pura e vida cotidiana impura, considerandose o protagonista da razão completa, mas está submerso numa vida imaginária, uma contradição que destrói a própria filosofia. Neste ponto, Lefebvre (1991b, p. 20) considera a visão crítica de Marx sobre a atitude meramente contemplativa do filósofo:

Existe um dilema. Ou ir mais longe que Hegel, buscando a
unidade entre a razão (filosófica) e a realidade (social), ou seja,
buscando a realização da filosofia - não aceitar mais a separação
do filosófico do não-filosófico, do superior e do inferior, do
espiritual e do material, do teórico e do prático, do espiritual e do
material, do teórico e do prático, do "cultivado" e do inculto,
procurando desde então uma transformação não apenas do
Estado, da vida política, da produção econômica ou da estrutura
jurídica e social, mas também do cotidiano.

Temos, aqui, o fundamento essencial que distingue a ontologia do ser social das outras ontologias elaboradas e defendidas por Husserl, Scheler, Heidegger e pelo existencialismo francês, explicitado por Lukács (2010, p.35) na obra Prolegômenos para uma Ontologia do Ser Social. Lukács (2010) problematiza os pressupostos destas "tendências de nosso tempo" que têm como denominador comum a fenomenologia e que estão baseadas numa concepção de "indivíduo isolado". Ele contrapõe seu argumento para posicionar o ponto de partida ontológico desde a vida cotidiana. Em outras palavras, o que Lukács (2010) pretende é, justamente, destacar a importância de uma concepção de ser humano de natureza orgânica e social, na qual o individualismo puramente idealista ou puramente biologicista não faz sentido. Assim, o ser humano não pode ser pensado isolado de seu próprio ser, expresso no cotidiano por ele mesmo construído.

Portanto, a crítica assumida tanto por Lukács quanto Lefebvre está dirigida justamente para o nível de pressupostos básicos, e não para o nível da validade lógica do pensamento (o que constitui apenas um critério gnosiológico). Para estes autores há uma realidade que contem condições objetivas que organizam o pensamento e são expressas na vida cotidiana, mas os homens nem sempre são conscientes dessas condições. Desse modo, é possível postular que a crítica marxista - que é crítica ontológica - é uma dupla análise no sentido de questionar tanto as figurações de mundo quanto os modos de vida concretos da vida diária dos indivíduos. A crítica ontológica, então, "figura o mundo social de maneira radicalmente distinta não só das formas de consciência do cotidiano dessa sociedade, mas também de suas formas de consciência 
científicas, que, nessa condição, são obviamente plausíveis, empiricamente válidas, embora criticáveis, como o são por Marx" (DUAYER, 2012, p. 41).

A partir dessa dupla crítica, e considerando que tanto Lukács quanto Lefebvre compartilham a mesma base ontológica, pode-se agora explorar o que cada um deles assume como ideologia.

\section{Lukács e as ideologias como mediações da ação humana}

Agora é preciso retomar a distinção entre a abordagem neutra e a crítica-negativa das ideologias. Também é preciso esclarecer que nem toda aproximação crítica-negativa assume uma postura marxista. Nesse sentido, segundo Vaisman (2010), Lukács utiliza um critério ontológico para determinar analiticamente as formações ideológicas, em contraposição ao critério gnosiológico. Esta contraposição refere-se à preocupação (gnosiológica) no campo da teoria do conhecimento pela natureza, origem e alcance dos postulados que ambicionam ser científicos. Assim, já no século XVIII, o filósofo empirista Francis Bacon pretendia “o pleno desenvolvimento do conhecimento humano. Era preciso evitar tanto a fé cega na autoridade, como a aceitação acrítica das opiniões convencionais" (LENK, 1971, p. 10). Deste modo, o problema da ciência é determinar as falsas ideias para garantir seu progresso, evitando o "desvio ideológico", colocando a pretensão de uma espécie de distanciamento entre a verdade e as interpretações humanas. A dificuldade desta postura é que ela coloca o homem fora da realidade estudada pela ciência, como se eles (o mundo e o homem) fossem entidades separadas. Em consequência, Lukács tenta recuperar a afirmação contida no pensamento marxiano para reconhecer o caráter do "homem ativo no mundo". Essa afirmação, que problematiza a separação entre o mundo e o homem (que é a separação entre natureza e sociedade), é, justamente um postulado ontológico, precisamente porque coloca outra concepção, outro princípio fundamental sobre o que o mundo é. Assim,

A análise do fenômeno ideológico a partir de uma perspectiva fundamentada gnosiologicamente é, na verdade, o resultado de uma tendência que vem se desenvolvendo há, praticamente, dois séculos no campo da filosofia. [...] Ou seja, o fato de o critério gnosiológico ter se tornado o critério fundamental e praticamente exclusivo na determinação do que é e do que não é ideologia deriva do predomínio no campo filosófico da questão do conhecimento, que acabou por deprimir o interesse pela questão ontológica. [...] Segundo a argumentação lukacsiana, no entanto, é impossível negar a questão do ser, na medida em que ela se encontra intimamente ligada à vida e à práxis (VAISMAN, 2010, p. 44-45). 
Como já foi dito, com Lukács é superada a crítica gnosiológica sobre o conhecimento, em termos de enunciados verdadeiros ou falsos. Ao mesmo tempo, é recuperada a crítica ontológica do marxismo, que reconhece o homem como ativo no seu mundo real, "um ser prático que responde" (LUKÁCS, 1978, p. 5; 1981, p. 464).

Assim, um ser que dá respostas é um ser que reage a alternativas que lhe são colocadas pela realidade objetiva, retendo certos elementos que nesta existem e transformando-os em perguntas, para as quais procura a melhor resposta possível. Em outras palavras, o homem é um ser que responde ao seu ambiente e, ao fazê-lo, ele próprio elabora os problemas a serem respondidos e lhes dá as respostas possíveis naquele momento (VAISMAN, 2010, p. 46-47).

Temos aqui a grande importância da consciência como característica que permite ao homem discernir, mesmo sem conhecimento pleno de todos os aspectos envolvidos na resolução de cada problema, entre suas possíveis respostas. Em consequência, o homem adquire, na ontologia do ser social, a faculdade de idear suas ações. Aqui reside a importância da noção de pôr teleológico: "todo o ato social surge, portanto, de uma decisão entre alternativas acerca de posições ${ }^{5}$ teleológicas futuras" (LUKÁCS, 1978, p. 6).

Agora, é preciso distinguir entre dois tipos de pores teleológicos. Em primeiro lugar, os pores teleológicos típicos da esfera econômica. Em segundo lugar, os pores teleológicos secundários, "que não pertencem à esfera econômica propriamente dita, mas de cuja existência esta depende para se manter e reproduzir [...]. É o caso das atividades não econômicas, "organizadoras da sociedade" " (VAISMAN, 2010, p. 47). Desse modo, Lukács coloca os pores teleológicos como formações ideais, produtos da consciência que agem entre a ação e a prévia ideação. A tomada de decisões, ou seja, as respostas do homem perante seus problemas são feitas através do momento ideal, quer dizer, uma prévia ideação consciente, e pode estar focada em dois planos. Assim, essas respostas

[...] podem visar à solução de problemas colocados no nível imediato, na própria vida cotidiana, ou podem estar voltadas à solução de problemas de caráter genérico. Em ambos os planos, elas são mediadas por algum tipo de produção espiritual, formando o conjunto das posições teológicas (excluído, aqui, o trabalho) em que a ideologia desempenha o papel de prévia-

\footnotetext{
${ }^{5}$ A diferença entre os termos "pôr" e "posição" faz parte de diferentes edições da obra de Lukács em língua portuguesa. No original alemão a expressão utilizada por Lukács é teleologische Setzung.
} 
ideação. Ou seja, a ideologia, em qualquer uma das suas formas, funciona como o momento ideal, que antecede o desencadeamento da ação, nas posições teleológicas secundárias (VAISMAN, 2010, p. 49).

Assim, temos que as ideologias não são uma estrutura ou conteúdo representacional de grupos sobre algumas esferas da vida em geral. Elas são, na perspectiva lukacsiana, "instrumentos pelos quais são conscientizados e enfrentados os problemas que preenchem (a) cotidianidade" (LUKÁCS, 1981, v.II, p. 446). Seu caráter mediador entre a realidade cotidiana e a consciência que dá respostas diante dessa mesma realidade leva a considerar as ideologias como artifícios que estão ligados inevitavelmente à ação dos homens. Portanto

[...] do ponto de vista ontológico, ideologia e existência social (em qualquer nível de desenvolvimento) são realidades inseparáveis. Ou seja, onde quer que se manifeste o ser social há problemas a resolver e respostas que visam à solução destes; é precisamente nesse processo que o fenômeno ideológico é gerado e tem seu campo de operações (VAISMAN, 2010, p. 49).

Voltando para o critério ontológico (em contraposição ao critério gnosiológico) como parâmetro para determinar se uma formação é ou não ideológica, é preciso salientar que qualquer "produto espiritual" não é propriamente uma ideologia. O caráter ideológico, como já foi dito, não depende da veracidade ou falsidade dos enunciados. Ele depende da sua função $^{6}$ na resolução de conflitos sociais. Por exemplo, no caso das teorias científicas, elas são ideologias, ao se tornarem instrumentos na resolução de conflitos. Por isso, "falar de ideologia em termos ontológico-práticos significa, portanto, analisar este fenômeno essencialmente pela função social que desempenha, ou seja, enquanto veículo de conscientização e prévia-ideação da prática social dos homens" (VAISMAN, 2010, p. 51).

${ }^{6}$ Em razão de que o uso do termo "função" pode referir ao arcabouço teórico funcionalista de Parsons (1973), resulta importante explicar o sentido empregado neste artigo. Para o funcionalismo, a função social consiste no papel do indivíduo no contexto do sistema, que é o ordenamento social, assumido como dado. Mas também, a preocupação dos funcionalistas está focada na ação individual que contribui para a conservação das condições que possibilitam a existência do sistema. Por outro lado, o uso do termo aqui é colocado no sentido de desvendar as implicações concretas das ideologias (quer dizer: suas operações materiais) sobre o ser social e suas particularidades no mundo concreto. Nesse sentido, o importante a ser especificado é justamente a análise materialista das ideologias, no intuito de superar as aproximações neutras e subjetivistas. Este artigo de maneira nenhuma sugere o estudo das funções em termos de papéis. Pelo contrário, pretende oferecer elementos para uma crítica ontológica das ideologias como formas de consciência que, mesmo que sejam elaborações abstratas, têm implicações práticas, especialmente na harmonização das contradições próprias da sociedade de classes. Por isso, examinar criticamente as implicações práticas de essas formas de consciência resulta ser radicalmente distinto de estudar os papéis exercidos. 
De fato, para Lukács (2012, p. 38), independentemente de ser correta ou não, a ideologia é uma espécie de meio não só para resolver problemas da existência humana, mas também para combater conflitos sociais. Ela funciona "como veículo de conscientização e prévia-ideação da prática social dos homens". A ideologia é, antes de tudo, "uma forma de elaboração ideal da realidade que serve para tornar a práxis social dos homens consciente e operativa". Portanto, a questão central é que a ideologia conduz à ação como ferramenta de luta nos conflitos sociais. Ela é, então, um dispositivo de atuação na prática, uma função em termos de dispositivo para a ação.

Até agora foi dito que existem dois critérios para determinar o que é uma ideologia: o gnosiológico e o ontológico. Também foi dito que neste ensaio será considerado o critério ontológico na perspectiva do Lukács. Ou seja, o que é ou não ideológico, depende da função mediadora da forma de consciência à condução da ação para a resolução de conflitos sociais. Aqui vale mencionar que a resolução dos conflitos sociais não é pensada de modo harmônico, ela deve considerar processos de dominação que contem contradições e, portanto, a resolução é sempre conflitiva, gerando uma nova contradição. Desse modo, os elementos de uma ideologia "são utilizados para desempenhar papel importante no esforço de grupos sociais para resolver seus conflitos segundo seus interesses" (LUKÁCS, 2012, p. 43).

Agora, essa busca pela resolução de conflitos sociais através da mediação ideológica acontece, de fato, tanto no plano das questões mais genéricas (como no caso da filosofia burguesa), quanto no plano dos problemas imediatos e que, para Lukács, corresponde à vida cotidiana. Temos aqui que, nesse plano genérico, a crítica ontológica lukacsiana examina as formas de consciência como elas são na sua essência, como filosofia burguesa e, portanto, ideologias. Essa constatação leva, então, a considerar que as ideologias podem constituir também estratagemas que afastam o pensamento humano das possibilidades de dar conta da realidade como ela é. Assim, considero importante destacar que, com Lukács, houve uma restauração do que é real:

[...] a tematização lukacsiana de ideologia se fundamenta na constatação ontológica preliminar, contida na afirmação do pensamento marxiano, que é precisamente o reconhecimento do homem ativo no mundo real, ou seja, o mundo real existe e essa é uma constatação feita pelo homem ativo no mundo. Em decorrência, este mundo real é capturável pelo homem, pelo seu entendimento. Em síntese, a concepção ontológica da qual Lukács parte é a de que: o homem ativo no mundo real é capaz de capturar o realmente existente (VAISMAN, 2010, p. 44). 
Assim, fica constatado o primeiro movimento proposto neste ensaio: a função das ideologias como formas de consciência - tais como a filosofia burguesa e a religião - que afastam o pensamento humano do real, reconhecendo a existência do mundo como ele é e como ele está sendo. Assumir esse princípio é reconhecer explicitamente o vigor de uma posição ontológica, optando por um pressuposto fundamental sobre o que o mundo é. De modo complementar, o real para a ontologia marxista é justamente a vida cotidiana dos indivíduos, o plano das práticas no qual as condições decorrentes das figurações de mundo são postas em ação. E é Lefebvre o autor que reflete sobre isso.

\section{Lefebvre e as ideologias como ilusões eficientes}

Para Lefebvre (1991a), as condições que são colocadas na vida cotidiana por parte das figurações de mundo existem e são ocultadas pelas ideologias, que tendem a privar os homens de sua consciência. As ideologias, então, são as máscaras que escondem a vida real. Portanto, a questão fundamental que emerge é por que os homens as aceitam? Nesse sentido, o projeto da crítica da vida cotidiana é justamente rasgar o véu da ideologia pelo qual a burguesia - através de seu projeto científico - tentou explicar a história para si mesma e torná-la aceitável para todos. "Assim, para alcançar a realidade devemos realmente rasgar o véu, o véu que está sempre nascendo e renascendo da vida cotidiana, e que mascara a vida cotidiana, juntamente com suas implicações mais profundas ou mais elevadas" (LEFEBVRE, 1991a, p. 57).

Para compreender o significado das ideologias para Lefebvre (1991a, p. 76), é importante comentar duas categorias fundamentais que estão no fundamento do seu estudo sobre a vida cotidiana: "a teoria da alienação e do "homem total" permanecem como a força oculta que rege a crítica da vida cotidiana. Elas permitem-nos representar o desenvolvimento social como um todo e determinar a direção em que ele vai".

A primeira questão, a alienação, pode ser entendida (de modo muito sintético) como uma prática na qual o homem se torna alheio ou estranho aos produtos resultantes da sua própria atividade. Essa prática leva à perda da essência humana, portanto é importante considerar que o que o ser humano é emerge a partir da consciência sobre o mundo e sobre si mesmo. No caso da alienação no trabalho, nos Manuscritos Econômicos e Filosóficos, Marx (2008, p. 84 - 85) refere:

A atividade vital consciente distingue o homem imediatamente da atividade vital animal. Justamente, [e] só por isso, ele é um ser genérico. Ou ele somente é um ser consciente, isto é, a sua própria vida lhe é objeto, precisamente porque é um ser genérico. 
Eis por que a sua atividade é atividade livre. O trabalho estranhado inverte a relação a tal ponto que o homem, precisamente porque é um ser consciente, faz da sua atividade vital, da sua essência, apenas um meio para sua existência (MARX, 2008, p. 84-45).

Assim, o ponto de partida é a produção e a reprodução da vida humana. Produzir no sentido de criar é a atividade essencial do ser humano, é o elemento diferenciador. Ele não se limita a tomar da natureza, mas deliberadamente pretende modificá-la. Por isso, o trabalho é a chave para entender o conceito de ser humano. Trabalho, como atividade produtiva livre é a atividade em que os seres humanos expressam a sua humanidade, a sua verdadeira natureza. Tudo o que é produzido, desta forma, é a essência da vida humana que se transforma em um objeto físico e, portanto, fora do produtor. Na sociedade de classes, o trabalhador não controla os produtos do seu trabalho, eles são estranhos ao trabalhador.

Lefebvre (1991a, p. 53) construiu a crítica da vida cotidiana em cima do conceito de alienação. Já no século XX ele se pergunta: "Por que o conceito de alienação é tratado com tal desconfiança? Por que o hegelianismo nos primeiros escritos de Marx é rejeitado? De onde vem a tendência a separar Marx de suas raízes, e seus trabalhos científicos maduros de seus primeiros escritos? Ou a tendência para datar e determinar a formação de marxismo de seus escritos políticos?". A esse respeito, ele responde que a questão é decorrente de uma espécie de simplificação empirista e de dogmatismo filosófico.

Tentando resgatar e ligar o conceito de alienação com a vida cotidiana, Lefebvre (1991, p. 58) coloca as diferentes expressões desta prática na sociedade capitalista além da visão restrita à esfera puramente econômica:

Mas a alienação correspondente aqui é mais abrangente. Ela engloba a vida na sua totalidade. Na sociedade capitalista, o dinheiro - a externalização das relações entre os seres humanos por meio de mercadorias - assume um poder absoluto. Mas isso é apenas a alienação econômica: o dinheiro como fetiche, objetivado fora dos homens, que funciona por si mesmo, é um dos objetos estudados pela ciência chamada economia política. Esta alienação econômica, embora seja uma parte integrante de alienação total, não é senão um dos seus aspectos.

Além disso, no volume II da Crítica da Vida Cotidiana Lefebvre (2002, p. 206) postula algumas "proposições" em torno deste conceito: 1) não existe alienação absoluta nem desalienação absoluta; 2) essas possibilidades só podem ser compreendidas em termos de movimento em situações concretas; 3) uma maior (ou menor) consciência possibilita o 
movimento entre a alienação e a desalienação; 4) a reificação (transformar uma ideia em uma coisa) é só um caso extremo de alienação. Ao mesmo tempo, para o homem, a alienação não é seu destino, "é através do conhecimento que o proletário se libera e começa a superar de forma ativa sua condição" (LEFEBVRE, 1991a, p. 144).

Esta ampliação do conceito de alienação para outras esferas da vida (da religião, da política, do social) permite atrelar a noção de totalidade e sua expressão na vida cotidiana. Para Lefebvre (1991a) a totalidade é uma noção que se contrapõe às tendências fragmentárias da filosofia burguesa e sua insistência em considerar o indivíduo como um ser isolado, atomizado na divisão do trabalho. "O homem total é apenas uma figura em um horizonte distante além da nossa visão presente. Ele é um limite, uma ideia, e não um fato histórico. E, no entanto, devemos historicizar a noção, pensando nisso histórica e socialmente" (LEFEBVRE, 1991a, p. 66).

Se formos obrigados para uma definição precisa do cotidiano, vamos começar a defini-lo negativamente. Se removermos as actividades delimitadas e especializadas (técnicas, trabalho parcelado, cultura, ética) e valores suportados, o que resta? Nada. Dizem alguns, os positivistas, os cientistas. Tudo, ou seja, o ser mais profundo, a essência, existência, dizem alguns filósofos e metafísicos. Nós dizemos: "Alguma coisa: a substância do homem, a matéria humana, o que permite lhe viver, o resíduo e, de repente, seus desejos, suas habilidades, suas possibilidades, suas relações essenciais com os produtos e outros seres humanos, seus ritmos, através dos quais é possível passar de uma atividade delimitada para outra completamente distinta, seu tempo e seu espaço ou espaços, conflitos... (LEFEBVRE, 1978, 88).

Então, estudar criticamente a vida cotidiana implica reconstruir as múltiplas determinações e contradições da realidade,

Assim, o evento mais simples - uma mulher compra uma libra de açúcar, por exemplo - deve ser analisado. O conhecimento vai entender o que está escondido dentro dele. Para entender este evento simples, não é suficiente apenas descrevê-lo; a investigação irá divulgar um emaranhado de razões e causas, de essências e "esferas": a vida da mulher, sua biografia, seu trabalho, sua família, sua classe, seu orçamento, seus hábitos alimentares, como ela usa seu dinheiro, suas opiniões e suas ideias, o estado do mercado, etc. Por fim, vou ter entendido a soma total da sociedade capitalista, a nação e sua história. E, embora o que eu compreender se torne mais e mais profundo, ele está contido, desde o início, nos casos pouco originais. Então, agora eu vejo os eventos humildes da vida quotidiana como tendo dois lados: um pequeno, individual, acontecimento fortuito - e, ao mesmo tempo, um evento social infinitamente complexo, mais rico do que muitas "essências" contidas dentro de si. O 
fenômeno social pode ser definido como a união das duas partes. Resta para nós, explicar porque a infinita complexidade desses eventos está escondida, e para descobrir porque - e isso também faz parte da sua realidade - eles parecem ser tão humildes. É, realmente, uma questão das superestruturas? São as superestruturas só o assunto? Não: É uma questão de superestruturas apenas na medida como eles são criados a cada instante da vida cotidiana e na prática social - na medida em que eles estão constantemente descendo para penetrar esses domínios desde acima (LEFEBVRE, 1991a p. 57).

Para Lefebvre (1991a), é particularmente importante dar conta da vida cotidiana justamente porque ela permite caracterizar situações concretas de alienação no contexto da sociedade burguesa. Ela evidencia as situações em que o trabalho produz não somente coisas e riqueza, mas também alienação e miséria. No trabalho alienado o homem é afastado do seu ser genérico, de seu caráter criativo, porque a divisão do trabalho atomiza. A alienação não está determinada pela propriedade (ou não propriedade) dos meios de produção, mas sim pelo afastamento do que o homem é na atividade produtiva fragmentada. Por isso, é importante ter consciência dos processos de alienação para buscar saídas, inclusive na ação criadora das artes: especialmente em obras fílmicas e da literatura. A vida cotidiana, então, mesmo revelando trivialidades e banalidades, é justamente o espaço em que acontecem as grandes decisões que modificam incessantemente a história.

No livro A Vida Cotidiana no Mundo Moderno, Lefebvre (1968) começa sua análise considerando categorias literárias como os referenciais de lugar, as pluralidades de sentido, a transposição dos significados, entre outros, para pensar a vida cotidiana de modo inseparável das rotinas formais. A vida cotidiana não é o momento residual que as pessoas vivenciam fora das atividades consideradas importantes. Nesse sentido ele postula que:

Há um clichê que, com algum grau de razão, compara momentos criativos com os topos das montanhas e o tempo cotidiano com planícies, ou com pântanos. A imagem que o leitor encontrará neste livro difere desta metáfora geralmente aceita. Aqui, a vida cotidiana é comparada com o solo fértil. Uma paisagem sem flores ou magníficas florestas pode ser deprimente para o transeunte; mas as flores e as árvores não devem fazer-nos esquecer a terra que as sustenta. [...] A vida cotidiana está profundamente relacionada com todas as atividades, as abarca com todas as suas diferenças e conflitos; é o seu ponto de encontro, o seu vínculo, seu terreno comum. E é na vida cotidiana onde toma forma a soma total dos relacionamentos que fazem o ser humano e cada ser humano um todo. Nela, expressam-se e realizam-se esses relacionamentos que põem em jogo a totalidade do real, embora sempre parcial e incompleta: 
amizade, companheirismo, amor, a necessidade de comunicar, jogar, etc. (LEFEBVRE, 1991a, p. 87).

Como já foi dito, a vida cotidiana não acontece só num local específico, como por exemplo, o local de trabalho; isso seria fazer um recorte próprio das ciências sociais tradicionais que Lefebvre (1991a) chama de "ciência burguesa", e que gera um conhecimento parcial e artificial. Assim, é possível dar conta da vida cotidiana no trabalho, na escola, no lar, na igreja, nas ruas, nos bairros, nos bares, no sonho, no sono e na vigília, na linguagem falada, escrita e cantada, nas festas, nos rituais, nos confrontos, nas lutas, no amor, na ciência, no passado e no possível. Estas dimensões podem constituir o grande campo de pesquisa da vida cotidiana sem fragmentar sua análise, procurando encadeamentos na totalidade e sem perder a perspectiva crítica.

Para resumir, o trabalho, o lazer, a vida familiar e a vida privada compõem um todo que podemos chamar de uma "estrutura global" ou "totalidade" na condição que nós destacamos como histórica, mudando, de natureza transitória. Se considerarmos a crítica da vida cotidiana como um aspecto de uma sociologia concreta, podemos prever uma ampla indagação que irá olhar para a vida profissional, vida familiar e atividades de lazer em termos de suas muitas faces de interações. Nossa preocupação particular será para extrair o que é vivido, novo, positivo - as necessidades e realizações de valor - desde os elementos

Agora, voltando para as ideologias, e lembrando que para Lefebvre (1991a) a teoria da alienação e o horizonte da totalidade constituem dois fundamentos da crítica da vida cotidiana, vale a pena retomar sua definição explícita sobre ideologias, em coincidência com Lukács (2010) a propósito das figurações, como no caso da filosofia burguesa, que explicam o mundo:

Os conhecimentos nascem no nível das superestruturas relacionadas com as ideologias. Ora, eles são eficazes, pois a ciência intervém na produção material. E o que é uma ideologia? Essa mistura de conhecimentos, de interpretações (religiosas, filosóficas) do mundo e do saber, enfim, essa mistura de ilusões pode chamar-se "cultura". Mas o que é uma cultura? É também uma práxis. É um modo de repartir os recursos da sociedade e, por conseguinte, de orientar a produção. É uma maneira de produzir, no sentido forte do termo. É uma fonte de ações e de atividades ideologicamente motivadas (LEFEBVRE, 1991b, p. 38).

Este tratamento das ideologias como mistura de ilusões está ligado à materialidade no sentido de que resolvem problemas cotidianos dos homens e, portanto, são eficientes porque permitem solucionar 
individualmente as contradições impostas pelas condições concretas da vida. Lefebvre (1991a, p. 93) chama a atenção para o fato de que:

[...] esta consciência é, portanto, determinada por condições objetivas (econômicas, sociais, mas também fisiológicas, etc.); no entanto, o indivíduo não tem consciência destas condições; isso é assim, precisamente, na medida em que não é consciente de que elas o determinam. Tal situação complexa e contraditória dá origem a uma multiplicidade de problemas. $\mathrm{O}$ indivíduo (neste caso, o indivíduo burguês) deve resolvê-los; ele procura uma solução, conscientemente. Ele procura as ideologias e doutrinas morais para uma imagem de si mesmo. As soluções e possibilidades assim reveladas e representadas - através de uma mistura de ficções ideológicas e momentos de consciência - são verdadeiras ou falsas, ilusórias ou válidas; elas levam a falhas mais ou menos bem sucedidas, e também para combinações de sucesso e fracasso. Isso é possível para o sucesso de ter qualquer relação objetiva com a ideologia.

Um dos exemplos mais ilustrativos para compreender o fato de que as ideologias podem ser tomadas como ilusões eficientes é, justamente, o caso das religiões:

Assim religiões, projetos teológicos ou metafísicos, foram autênticas tentativas para reconciliar o homem consigo mesmo, $\mathrm{o}$ ser humano com a natureza, o indivíduo com o social. Elas têm alcançado tanto a sua coerência interna quanto sua entrada na vida destas tentativas, sob a forma de ações, e a busca de um estilo. O fervor religioso e crença num Deus deram expressão simbólica para a unidade dos elementos do ser humano, e projetou essa unidade fora do homem (LEFEBVRE, 1991a, p. 73).

Agora, no plano das relações entre classes, a sociedade burguesa também cria essa ilusão eficiente focada na harmonização das suas relações contraditórias:

E, assim, a burguesia pode exercer permanentemente, e até certo ponto sucesso, pressões sobre o proletariado - uma influência que tende a dividi-lo em indivíduos. O individualismo não é simplesmente uma teoria, mas também um fato e uma arma de classe. Não é simplesmente através de suas idéias e sua concepção do mundo que a burguesia exerce esse influencia. Reconhecidamente, o seu individualismo teórico, e seu "atomismo social", não são ineficazes, mas a maneira como ele realmente organiza a vida cotidiana, lazer, vida familiar, etc., é infinitamente mais importante. [...] Esta representação é nada mais do que uma ideologia, ou seja, um meio de ação, uma ilusão eficiente - e a consciência da burguesa média, e acima de tudo do pequeno burguês, é levada por ela. Não são tanto o governo, os braços políticos e policiais da burguesia; no nível político, que a 
burguesia compreende perfeitamente sobre massas e classes (LEFEBVRE, 1991a, p. 151-152)

Assim, fica claro que, também para Lefebvre a importância da ideologia, independentemente de seu valor gnosiológico, pode ser identificada a partir da sua função na resolução das contradições. Desse modo, no plano político,

Quando um proletário acredita que ele é simplesmente um "cidadão" comparável a qualquer outro cidadão, ou que ele está destinado a trabalhar porque está escrito por toda a eternidade que todo homem "deve ganhar o pão com o suor do seu rosto", ele está sendo mistificado. Mas como e por quê? Porque, para ele, o seu trabalho é uma carga pesada em termos reais, e - sob certas pressões - se ele não entende (ou sabe) que o trabalho pode e deve tornar-se outra coisa, ele bem pode interpretá-lo como uma fatalidade da condição humana ou como seu próprio infortúnio pessoal. Mas a crença na igualdade política e jurídica do indivíduo, que é uma crença ilusória para qualquer proletário que a tome pelo seu valor aparente, se transforma em um meio admirável de ação tão logo ele começa a insistir que a democracia deixe de ser uma fiç̧ão jurídica e política. O estudo das mistificações revela sua ambiguidade - uma ambiguidade que primeiro as torna aceitáveis mas que depois faz que seja possível deixá-las atrás (LEFEBVRE, 1991a, p. 146).

Consequentemente Lefebvre (1991a) constrói suas proposições a partir do aprofundamento e aplicação de categorias como ambiguidade, $\mathrm{o}$ campo semântico, a teoria dos momentos e outros elementos que auxiliam o projeto de longo prazo:

Fica, então, aberto apenas um caminho: descrever e analisar o cotidiano a partir da filosofia, para mostrar sua dualidade, sua decadência e fecundidade, sua miséria e riqueza. Isso implica o projeto revolucionário de um parto que tirasse do cotidiano a atividade criadora inerente, a obra inacabada (LEFEBVRE, 1991b, p. 18)

Por tanto, pode se encontrar na obra do Lefebvre (1991a) um campo de fundamentos teóricos baseados na ontologia marxista, assinalada também por Lukács (2012). 


\title{
Considerações finais: A crítica das ideologias como uma dupla crítica
}

As ideologias podem ser compreendidas através de uma dupla análise como base para desenvolver a pretensão Lukacsiana de uma crítica ontológica, tanto em termos da vida cotidiana quanto no plano das formações objetivas da filosofia burguesa:

\begin{abstract}
De um lado, uma consideração ontológica do ser social é impossível sem procurarmos seu primeiro ponto de partida nos fatos mais simples da vida cotidiana dos homens. [...] Mas, por outro lado - devido igualmente ao fato básico próprio do ser humano de que nunca somos capazes de ter um conhecimento total de todos os componentes de nossas decisões e suas consequências -, também na vida cotidiana o verdadeiro ser muitas vezes se revela de maneira altamente distorcida. Em parte, os modos de manifestação imediata encobrem o essencial do ser efetivo, em parte nós mesmos projetamos no ser, com silogismos analógicos precipitados, determinações que são totalmente estranhas a ele, apenas imaginadas por nós; além disso, confundimos com o próprio ser os meios com que tomamos consciência de momentos determinados do ser etc. Portanto, é preciso partir da imediaticidade da vida cotidiana, e ao mesmo tempo ir além dela, para poder apreender o ser como autêntico em si. Mas, simultaneamente, também é preciso que os mais indispensáveis meios de controle do ser pelo pensamento sejam submetidos a uma permanente consideração crítica, tendo por base sua constituição ontológica mais simples. As interrelações desses dois pontos de vista aparentemente opostos é que possibilitam uma aproximação daquilo que o ser, como ente, verdadeiramente é (LUKACS, 2010. p. 37).
\end{abstract}

Temos, aqui, uma espécie de dupla coordenada para guiar uma aproximação entre o que é o ser e o que existe na realidade. Essa busca para alcançar o real leva a refletir sobre que é o real. Em outros termos é este o projeto de restaurar a crítica ontológica iniciada por Marx.

Nesse sentido, as ideologias não podem ser analisadas sem considerar a realidade social dos homens. Isso em contraposição tanto à visão puramente representacional no plano da subjetividade de indivíduos e grupos, quanto no plano das formas de consciência burguesa expressas em teorias que ambicionam ser científicas. Por isso, as ideologias estão ligadas aos conflitos sociais próprios das contradições inerentes à vida social dos homens.

As ideologias fazem parte do processo das ações humanas sobre a realidade. Homem e realidade constituem uma unidade indivisível, e no processo de tomada de decisões, tanto no plano amplo das ideias quanto no plano concreto da vida cotidiana, as ideologias são tanto um meio para 
a ideação da realidade quanto um fim em si mesmas, já que instituem formas de consciência alheias à essência do ser social.

Assim, as teorias baseadas nas ontologias positivista e fenomenológica, harmonizam as contradições. Elas resolvem no plano ideal e na prática, os conflitos pela eliminação das manifestações de resistência perante essa realidade, como no caso do individualismo já apontado por Lukács e Lefebvre.

Superar a visão neutra das ideologias para um programa de pesquisa da realidade social atual implica então, dar conta das ideologias com sua dupla função prática. Isso abarca a dupla crítica ontológica, quer dizer, dos presupostos fundantes, estruturais, das teorias científicas e no plano da vida cotidiana.

Essa dupla crítica configura uma unidade de análise complementar que permite aproximar-se da figuração de mundo imposta pelo modo de produção em qualquer das suas fases, especialmente no mundo contemporâneo, justamente para problematizar sua naturalização como destino inevitavelmente trágico do ser humano. Desse modo, a dupla crítica permitirá construir um conhecimento autêntico visando um outro mundo possível.

\section{Referências}

DUAYER, Mario. Marx e a crítica ontológica da sociedade capitalista: crítica do trabalho. Revista Em Pauta, Rio de Janeiro, 2012, n. 29, v. 10, p. 35-47. Disponível em: http://www.epublicacoes.uerj.br/index.php/revistaempauta/article/view/3880.

Acesso em Acesso em 31 mai. 2016.

HELLER, Agnes. Sociología de la vida cotidiana. Barcelona: Península, 2002.

KONDER, Leandro. A questão da ideologia. São Paulo: Companhia das Letras, 2002.

LEFEBVRE, Henri. De lo rural a lo urbano. Barcelona: Ediciones Península, 1978.

Critique of everyday life. London: Verso, 1991a, v. 1.

A vida cotidiana no mundo moderno. São Paulo: Ática, $1991 b$.

Critique of everyday life. London: Verso, 2002, v. 2. 
LENK, Kurt. El Concepto de ideologia, Buenos Aires, Amorrortu Editores, 1971.

LUKÁCS, Gyorgy. Prolegômenos para uma ontologia do ser social. Campinas: Boitempo, 2010.

LUKÁCS, Gyorgy. Ontologia do ser social. Campinas: Boitempo, 2012.

MARX, Karl. Manuscritos econômicos e filosóficos. São Paulo: Boitempo, 2008.

MARX, Karl e ENGELS, Friedrich. A ideologia alemã. São Paulo: Boitempo. 2007.

PARSONS, Talcott. O conceito de sistema social. In: CARDOSO, Fernando Henrique; IANNI, Octavio (Orgs.) Homem e sociedade: leituras básicas de sociologia. São Paulo: Companhia Editora Nacional, 1973. p. 4755

STOPPINO, Mario. Ideologia. In: BOBBIO, Norberto, MATTEUCCI, Nicola \& PASQUINO, Gianfranco (Orgs.). Dicionário de política. Brasília: Editora da Universidade de Brasília, 1986.

TREBISTH, Michel. Preface in LEFEBVRE, Henri. Critique of everyday life Volume I: Introduction. London: Verso, 1991.

VAISMAN, Ester. A ideologia e sua determinação ontológica. Verinotio revista online - n. 12, Ano VI, out./2010. Disponível em: http://www.verinotio.org/conteudo/0.49365995032122.pdf. Acesso em 31 mai. 2016.

VAN DIJK, Teun. Ideología, una aproximación multidisciplinaria. Barcelona: Gedisa, 1999.

Submetido em: 07/12/2016

Aprovado em: 08/04/2017 